OPEN ACCESS

Edited by:

Carmen Fernández,

Stockholm University, Sweden

Reviewed by:

Silvia Ines Cazorla,

Centro de Referencia para Lactobacilos (CONICET), Argentina

Deguang Song,

Yale University, United States

*Correspondence:

Dongyan Shao

shaoyan@nwpu.edu.cn

Chunlan Xu

clxu@nwpu.edu.cn

Specialty section:

This article was submitted to

Mucosal Immunity,

a section of the journal

Frontiers in Immunology

Received: 16 July 2021 Accepted: 09 November 2021 Published: 25 November 2021

Citation:

Song X, Pi S, Gao Y, Zhou F, Yan S, Chen Y, Qiao L, Dou X, Shao D and $X u C$ (2021) The Role of Vasoactive Intestinal Peptide and Mast Cells in the

Regulatory Effect of Lactobacillus casei ATCC 393 on Intestinal Mucosal Immune Barrier.

Front. Immunol. 12:723173. doi: 10.3389/fimmu.2021.723173

\section{The Role of Vasoactive Intestinal Peptide and Mast Cells in the Regulatory Effect of Lactobacillus casei ATCC 393 on Intestinal Mucosal Immune Barrier}

\author{
Xiaofan Song, Shanyao Pi, Yueming Gao, Fengxia Zhou, Shuqi Yan, Yue Chen, Lei Qiao, \\ Xina Dou, Dongyan Shao * and Chunlan $X^{*}$

\begin{abstract}
The Key Laboratory for Space Bioscience and Biotechnology, School of Life Sciences, Northwestern Polytechnical
\end{abstract} \\ University, Xi'an, China
}

Vasoactive intestinal peptide (VIP) plays an important role in the neuro-endocrine-immune system. Mast cells (MCs) are important immune effector cells. This study was conducted to investigate the protective effect of $L$. casei ATCC 393 on Enterotoxigenic Escherichia coli (ETEC) K88-induced intestinal mucosal immune barrier injury and its association with VIP/MC signaling by in vitro experiments in cultures of porcine mucosal mast cells (PMMCs) and in vivo experiments using VIP receptor antagonist (aVIP) drug. The results showed that compared with the ETEC K88 and lipopolysaccharides (LPS)induced model groups, VIP pretreatment significantly inhibited the activation of MCs and the release of $\beta$-hexosaminidase ( $\beta$-hex), histamine and tryptase. Pretreatment with aVIP abolished the protective effect of $L$. casei ATCC 393 on ETEC K88-induced intestinal mucosal immune barrier dysfunction in C57BL/6 mice. Also, with the blocking of VIP signal transduction, the ETEC K88 infection increased serum inflammatory cytokines, and the numbers of degranulated MCs in ileum, which were decreased by administration of L. casei ATCC 393. In addition, VIP mediated the regulatory effect of L. casei ATCC 393 on intestinal microbiota in mice. These findings suggested that VIP may mediate the protective effect of L.casei ATCC 393 on intestinal mucosal immune barrier dysfunction via MCs.

Keywords: probiotic, Lactobacillus casei ATCC 393, mast cells, vasoactive intestinal peptide, mucosal immune, intestinal barrier

\section{INTRODUCTION}

The intestinal barrier is essential for maintaining intestinal homeostasis and health. It prevents the loss of water and electrolytes and the invasion of antigens and microorganisms $(1,2)$. Therefore, the integrity of the intestinal barrier is particularly important for human and animal health. One of the main causes of gastrointestinal diseases such as necrotizing enterocolitis, irritable bowel syndrome (IBS) and inflammatory bowel disease (IBD) is the impairment of intestinal epithelial 
barrier integrity $(3,4)$. The intestinal mucosal immune barrier is mainly composed of intestinal mucosal epithelial cells and intestinal associated lymphoid tissues. Intestinal mucosal immune cells mainly include lymphocytes, goblet cells, mast cells, etc. The intestinal microbiome as a key component of the intestinal barrier system are strongly associated with the host health (5). Lactobacillus casei (L. casei) strains are commonly added to yogurt and fermented dairy products to improve their health benefits (6). L. casei could relieves constipation and diarrhea $(7,8)$. L. casei has also shown promise in preventing or alleviating human IBDs (9). However, the attenuation of colitis by L. casei BL23 was found to be dependent on the dairy delivery matrix (10). The impact of L casei on the cecal microbiome and innate immune system is strain specific (11), and dose and time-dependent (12). L. casei expressing internalins A and B significantly reduced Listeria monocytogenesinduced cell cytotoxicity and epithelial barrier dysfunction (13). Moreover, L. casei ATCC 393 alleviated ETEC K88-induced intestinal barrier dysfunction via the toll-like receptors (TLRs)/ mast cells (MCs) pathway (14).

MCs are an important natural immune effector cells, which participate in mucosal immunomodulatory process by releasing cytokines. The activation and degranulation of MCs is involved in the regulation of variety of physiological and pathological conditions in various settings (15). The reversal of ion permeation and transmembrane transport of macromolecules by MCs stabilizers was demonstrated in animal studies (16). MCs serve as a line of defense against antigens entering the body, and contribute to maintain the homeostasis of the immune system (17). MCs express various receptors including pathogenassociated molecular patterns (PAMPs), vasoactive intestinal peptide receptors (VPACs), NOD-like receptors (NLRs) as well as TLRs, all of which are involved in MC activation and immune response (18). A variety of endogenous and exogenous drugs can stimulate MCs to release mediators. The impairment of the intestinal barrier is related to the increase of intracavity antigens entering the mucosa, which further promotes the activation of MCs in the mucosa inflammatory response and changes in MC-enteric nerve interaction (19). Vasoactive intestinal peptide (VIP) plays a crucial role in the neuroendocrine-immune system. Some studies have demonstrated the role of VIP in intestinal permeability regulation (20). Other studies have shown that MCs and VIP regulate the ileal barrier of healthy people and the stress response in rats through the VPAC1/VPAC2 receptors on the surface of MCs (21). An increase in plasma VIP levels was found in IBS patients and animal models. Also, intestinal epithelial permeability appears to be a positively correlated with mucosal MCs (22). However, the association of the protective effect of L. casei ATCC 393 on intestinal barrier function with VIP/MCs remains unclear.

This study was aimed to investigate the role of VIP in the protective effect of L. casei ATCC 393 on intestinal barrier dysfunction in mice challenged by ETEC K88 and its association with MCs. The ETEC K88 and LPS-induced VIPmediated regulatory effect on MCs activation, and its association with the protective effect of L. casei ATCC 393 on intestinal epithelial barrier function were evaluated through in vitro coculture experiments of porcine intestinal mucosal mast cells (PMMCs) with L. casei ATCC 393 and in vivo experiments using VIP receptor antagonist (aVIP) drug.

\section{MATERIALS AND METHODS}

\section{Bacterial Strains, Cell Line, and Reagents}

L. casei ATCC 393 and ETEC K88 strain were kept in our laboratory. PMMCs were purchased from Saiqi (Shanghai) Biological Engineering Co., Ltd (Cat \# CBR-131443). Man, Rogosa and Sharpe (MRS) broth (Cat \# CM1153B) was purchased from Oxoid (Basingstoke, UK). Luria-Bertani (LB) broth (Cat \# 12780052) were purchased from Gibco-Invitrogen. The reagents for cell culture were purchased from Invitrogen/ Gibco (Carlsbad, CA, USA). Enzyme-linked immunosorbent assay (ELISA) Kits for porcine tumor necrosis factor- $\alpha$ (TNF- $\alpha$, Cat\# JL13203), porcine and mouse interferon- $\gamma($ IFN- $\gamma$, Cat\# JL11792), porcine interleukin-6 (IL-6, Cat\# JL21880), porcine interleukin-8 (IL-8, Cat\#JL45446), porcine granulocyte-macrophage colony stimulating factor (GM-CSF, Cat\#JL21931), porcine $\beta$ hexosaminidase (Cat\# JL45717), porcine tryptase (Cat\# JL17996), and porcine histamine (Cat\#JL10076), and mouse TNF- $\alpha$ (Cat\#JL10484), mouse IFN- $\gamma$ (Cat\#JL10967), mouse IL-6 (Cat\#JL20268), mouse IL-1 $\beta$ (Cat\#JL18442), mouse $\beta$ hexosaminidase (Cat\#JL20214), mouse tryptase (Cat\#JL20445), mouse histamine (Cat\#JL10420), and mouse MPO (Cat\#JL10367) were purchased from Jianglaibio Co., Ltd (Shanghai, China). The bicinchoninic acid (BCA) protein assay kit (Cat\#P0012S) was purchased from Beyotime Biotechnology (Shanghai, China). VIP and VIP receptor antagonist $\left(\mathrm{VIP}_{6-28}\right.$, aVIP) were synthesized by Shanghai Qiangyao Biological Co.,Ltd (Shanghai, China). Lipopolysaccharides (LPS, Cat\#L4391) from Escherichia coli O111:B4 was purchased from Sigma Aldrich Company (Saint Louis, MO, USA). Primary antibodies for

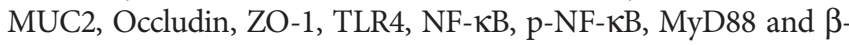
actin were purchased from ABclonal Company (Wuhan, China).

\section{Cell Culture Conditions}

PMMCs were cultured in high glucose Dulbecco's modified Eagles's medium (DMEM) supplemented with 10\% fetal bovine serum (FBS) and $1 \%$ antibiotic mixture $(100 \mathrm{U} / \mathrm{mL}$ of penicillin and $100 \mu \mathrm{g} / \mathrm{mL}$ streptomycin) in an incubator at $37^{\circ} \mathrm{C}$ in a humidified atmosphere with $5 \% \mathrm{CO}_{2}$.

\section{Bacterial Culture Conditions}

L. casei ATCC 393 was incubated in MRS broth at $37^{\circ} \mathrm{C}$ for $24 \mathrm{~h}$ without shaking. ETEC K88 was cultured in LB broth with shaking at a speed of $120 \mathrm{rpm}$ at $37^{\circ} \mathrm{C}$ overnight. Bacteria pellets were collected by centrifuging at $5,000 \times \mathrm{g}$ at $4^{\circ} \mathrm{C}$ for 10 $\mathrm{min}$, and then washed with phosphate-buffered saline (PBS). The obtained bacteria were suspended in FBS-free cell culture medium and diluted to different concentrations. The supernatants of $1 \times 10^{8} \mathrm{CFU} / \mathrm{mL}$ L. casei ATCC 393 and $1 \times 10^{8}$ $\mathrm{CFU} / \mathrm{mL}$ of ETEC K88 culture medium were separately 
harvested by centrifugation at $5000 \times \mathrm{g}$ at $4^{\circ} \mathrm{C}$ for $10 \mathrm{~min}$. The bacterial supernatants and bacterial resuspension solution were collected and used for subsequent experiments.

\section{Effect of VIP, aVIP and L. casei ATCC 393 on PMMCs Activation}

PMMCs were seeded at a concentration of $4 \times 10^{5}$ cells $/ \mathrm{mL}$ in 24 well cell culture plates and cultured at $37^{\circ} \mathrm{C}$ for $24 \mathrm{~h}$. Normal control cells were exposed to $1 \mathrm{~mL}$ of FBS-free DMEM. For the L. casei ATCC 393 treatment group, $1 \mathrm{~mL}$ of $1 \times 10^{8} \mathrm{CFU} / \mathrm{mL}$ of $L$. casei ATCC 393 bacterial culture supernatants was added to each well. Other groups received $1 \mathrm{~mL}$ of FBS-free DMEM. VIP and aVIP treatment groups were administrated with $1 \mathrm{~mL}$ of FBS-free DMEM containing $0.1 \mu \mathrm{M}$ VIP and/or $0.1 \mu \mathrm{M}$ aVIP, respectively. The plates of all groups were incubated at $37^{\circ} \mathrm{C}$ for $12 \mathrm{~h}$. After the above treatments, supernatants of cell culture medium supernatants were collected, and the concentration of $\beta$-hexosaminidase, tryptase, and histamine were determined using the corresponding ELISA kits according to the manufacture's instruction.

\section{Effect of VIP and aVIP Interaction on the Activation of PMMCs}

PMMCs were seeded at a concentration of $4 \times 10^{5}$ cells $/ \mathrm{mL}$ in 24 well cell culture plates and cultured at $37^{\circ} \mathrm{C}$ for $24 \mathrm{~h}$. The cells were divided into four groups and treated accordingly: the normal control group received $1 \mathrm{~mL}$ of FBS-free DMEM; VIP and aVIP treatment group received $1 \mathrm{~mL}$ of FBS-free DMEM containing $0.1 \mu \mathrm{M}$ VIP or/and $0.1 \mu \mathrm{M}$ aVIP, respectively, and cultured at $37^{\circ} \mathrm{C}$ for $12 \mathrm{~h}$. Afterwards, the cell culture medium supernatants were collected, and the concentration of $\beta$ hexosaminidase, tryptase, and histamine were determined using corresponding ELISA kits.

\section{Effect of L.casei ATCC 393 on VIP- Mediated Activation of PMMCs}

PMMCs were inoculated at a density of $4 \times 10^{5}$ cells $/ \mathrm{mL}$ in sterile 24-well cell culture plate and cultured at $37^{\circ} \mathrm{C}$ for $24 \mathrm{~h}$ until the cell confluence reached higher than $90 \%$. Normal control cells received $1 \mathrm{~mL}$ of FBS-free DMEM. The VIP alone group was treated with $1 \mathrm{~mL}$ of FBS-free DMEM containing $0.1 \mu \mathrm{M}$ VIP for $12 \mathrm{~h}$. The L. casei ATCC 393 alone group was exposed to $1 \mathrm{~mL}$ of $1 \times 10^{8} \mathrm{CFU} / \mathrm{mL}$ L. casei ATCC 393 culture supernatant for $3 \mathrm{~h}$. The VIP and L. casei ATCC 393 co-cultured cells were first administered with $1 \mathrm{~mL}$ of $1 \times 10^{8} \mathrm{CFU} / \mathrm{mL}$ of L. casei ATCC 393 culture supernatant for $3 \mathrm{~h}$, then changed to $1 \mathrm{~mL}$ of FBS-free DMEM containing $0.1 \mu \mathrm{M}$ VIP and culured for $12 \mathrm{~h}$. Afterwards, the cell culture supernatants were collected, and the concentration of $\beta$-hexosaminidase, tryptase and histamine were determined using the corresponding ELISA kits.

\section{Effect of VIP and aVIP on ETEC K88 or LPS-Induced PMMCs Activation}

PMMCs were seeded at a density of $4 \times 10^{5}$ cells $/ \mathrm{mL}$ in sterile 24 well cell culture plates and cultured at $37^{\circ} \mathrm{C}$ for $24 \mathrm{~h}$. First, normal control cells were exposed to $1 \mathrm{~mL}$ of FBS-free DMEM, the VIP alone treatment group was given $1 \mathrm{~mL}$ of FBS-free
DMEM containing $0.1 \mu \mathrm{M}$ VIP, and the aVIP treatment group received $1 \mathrm{~mL}$ of FBS-free DMEM containing $0.1 \mu \mathrm{M}$ aVIP, and the aVIP-VIP co-treatment group received $1 \mathrm{~mL}$ of FBS-free DMEM containing $0.1 \mu \mathrm{M}$ aVIP and $0.1 \mu \mathrm{M}$ VIP. Then all group cells were cultured at $37^{\circ} \mathrm{C}$ for $12 \mathrm{~h}$. Control groups were exposed to $1 \mathrm{~mL}$ of FBS-free DMEM, other experimental groups were changed to $1 \mathrm{~mL}$ of $1 \times 10^{8} \mathrm{CFU} / \mathrm{mL}$ ETEC K88 culture supernatant or $1 \mathrm{~mL}$ of FBS-free DMEM containing $0.1 \mu \mathrm{M}$ of LPS. After additional incubation for $2 \mathrm{~h}$, cell culture medium supernatants were collected. The concentration of $\beta$ hexosaminidase, tryptase, histamine, IL-6, IL-8, TNF- $\gamma$ and GM-CSF were determined by the corresponding ELISA kits.

\section{Animal Experimental Design}

Animals can produce endogenous VIP, but whether it mediates the regulation of the $L$. casei ATCC 393 effect on intestinal barrier function remains unclear. We hypothesized that $L$. casei ATCC 393 can regulate the effect of pathogenic bacteria such as ETEC K88-induced intestinal mucosal MC activation and inhibit the release of MCs released mediators, regulate inflammatory responses, and further regulate intestinal barrier function through the binding of VIP and VIP receptors on the surface of intestinal mucosal MCs. To verify the above hypothesis, we conducted experiments to assess the effect of a VIP receptor antagonist (aVIP) in C57BL/6 mice challenged by ETEC K88. This animal experimental protocol was approved by the Laboratory Animal Welfare and Ethics Committee of Northwestern Polytechnical University and the experiment was conducted strictly in accordance with the International Laboratory Animal Assessment and Accreditation Committee guidelines for the care and use of laboratory animals. The 50 healthy male C57BL/6 mice (20 $\pm 2 \mathrm{~g})$ used in the experiment were purchased from the Experimental Animal Center of Xi'an Jiaotong University (Xi'an, Shaanxi, China). The entire feeding experiment was conducted at the Experimental Animal Center of Northwestern Polytechnical University. After an adaptive period of 7 days, the mice were randomly divided into five groups with 10 mice per group: normal control group, ETEC K88 infected group, L. casei ATCC 393 protective group, aVIP + ETEC K88 treatment group, L. casei ATCC 393 + aVIP + ETEC K88 treatment group. The living conditions were as follows: relative humidity of $55 \pm 5 \%$, ambient temperature of $22 \pm 5{ }^{\circ} \mathrm{C}$, and under a $12 \mathrm{~h}$ light and dark cycle. The experimental scheme is depicted in Figure 3A. The mice in the L. casei ATCC 393 protective group were orally administered with $200 \mu \mathrm{L}$ of $1 \times 10^{8}$ CFU/mL of L. casei ATCC 393 resuspension solution per day for 14 days. The other groups were orally given the same volume of MRS broth. On days 1, 3, 5, 7, 9, and 11, mice in the ETEC K88infected group were orally given $100 \mu \mathrm{L}$ of $1 \times 10^{8} \mathrm{CFU} / \mathrm{mL}$ ETEC K88 resuspension solution, and the other groups were given the same volume of LB broth. On days 0,5 and 10, the aVIP treatment groups were intraperitoneally (i.p.) injected with aVIP $(10 \mathrm{nmol} / \mathrm{kg} / \mathrm{BW})$. Other groups were i.p. injected with the same volume of normal saline. The body weight, diarrhea and mental status were observed and recorded daily. After the above treatments, mice were anesthetized with ether. Peripheral 
blood was drawn from mice and centrifuged immediately at $1,500 \times \mathrm{g}$ for $15 \mathrm{~min}$ at $4^{\circ} \mathrm{C}$ to obtain serum. Serum samples were stored at $-80^{\circ} \mathrm{C}$ until analyzed. Then, immediately the mice were dissected, the tissues of interest (the duodenum and ileum) were collected.

\section{Histological Analysis of Duodenum and Evaluation of Intestinal Barrier Function}

The duodenum is an important intestinal segment of the digestive tract for nutrient digestion and absorption. Its histology and morphology are closely related to intestinal function. The tissues samples of the proximal duodenum were fixed in $10 \%$ neutral buffer formalin, dehydrate, and paraffin-embedded. Then, the sections prepared from the paraffin-embedded tissue blocks were stained with hematoxylin-eosin (H\&E) and observed under a phasecontrast microscope for histological and morphological characterization of the duodenum. To further evaluate the changes in intestinal barrier function, the expression level of MUC2, Occludin, and ZO-1 proteins in duodenum were detected by immunofluorescence and Western Blot respectively. The expression levels of MUC2 and Reg3g genes were detected by qPCR. Primer sequences are shown in Table 1.

\section{Detection of Intestinal Immune Responses}

Intestinal mucosal MCs are key modulators of barrier function and homeostasis, which widely distributed in ileum. Therefore, the numbers of MCs and the degranulated MCs in proximal ileum were detected by toluidine blue (TB.) staining. Serum $\beta$ hexosaminidase, tryptase and MPO activities, as well as VIP, sIgA, histamine, TNF, IFN- $\gamma$, IL- 6 and IL- $1 \beta$ concentrations were determined by the corresponding ELISA kits according to the manufacture's instruction.

\section{Intestinal Microbiota Analysis}

To investigate the changes of intestinal microbiota, we detected the cecal contents of mice by $16 \mathrm{~S}$ rRNA amplicon sequencing. As in previous research methods, whole-genome DNA was extracted and sequenced for analysis (23). The sequences with similarity $\geq 97 \%$ were clustered. OTUs were assigned to each representative sequence in the cluster by searching against the GreenGene Database.

\section{Effects of aVIP and L. casei ATCC 393 on TLRs/MyD88/NF-кB Signaling Pathway}

To further explore the mechanism of the effect on intestinal immune barrier function, we detected the protein expression

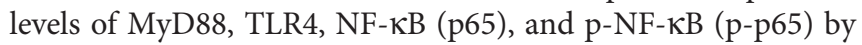
Western Blot.

\section{Statistical Analysis}

All experimental data were statistically analyzed using Graphpad Prism 5.0 statistical software (GraphPad Software Inc., San Diego, CA, USA) and are presented as the mean \pm standard error of mean (S.E.M.). The statistical significance was calculated by one-way analysis of variance (ANOVA) or Student's $t$-test.
TABLE 1 | Primer sequences of MUC2 and Reg3g genes for q-PCR.

\begin{tabular}{lcc}
\hline Gene product $^{\mathbf{a}}$ & \multicolumn{2}{c}{ Primer } \\
\cline { 2 - 3 } & Direction $^{\mathbf{b}}$ & Sequence (5'-3') \\
\hline MUC2 & $\mathrm{F}$ & CAGACTACACGACAGGTGGG \\
Reg3g & $\mathrm{R}$ & GTGGTGGTCGTTGATCCAGT \\
& $\mathrm{F}$ & ATCAGCTGTCCCAAAGGCTC \\
& $\mathrm{R}$ & CATTGGTTCCAAGCCCTCG
\end{tabular}

aMUC2, Mucin 2; Reg3g, Regenerating islet-derived protein III-gamma.

${ }^{b} \mathrm{~F}$, forward; $R$, reverse.

Differences were considered significant at $P<0.05$. All assays were performed in at triplicate three independent experiments.

\section{RESULTS}

\section{Effect of VIP, aVIP and L. casei ATCC 393 on PMMCs Activation}

As shown in Figure 1A, compared with the normal control group, exposure to L. casei ATCC 393 or VIP significantly induced the activation of PMMCs, and promoted the release of MCs-related mediators including $\beta$-hexosaminidase, tryptase and histamine. However, aVIP had no effect on PMMCs.

\section{Effect of Interaction Between VIP and aVIP on PMMCs Activation}

As shown in Figure 1B, compared with the normal control group, treatment with VIP significantly increased the concentration of $\beta$-hexosaminidase, tryptase and histamine in the supernatant of PMMCs. Exposure to aVIP alone had no effect on PMMCs. However, administration of aVIP significantly inhibited VIP-induced activation of PMMCs.

\section{Effect of VIP Mediated L. casei ATCC 393 on Activation of PMMCs}

As shown in Figure 1C, compared with the normal control group, both VIP and L. casei ATCC 393 treatments increased the $\beta$-hexosaminidase, tryptase and histamine concentration in the supernatant of PMMCs. However, L. casei ATCC 393 pretreatment significantly inhibited the VIP-induced activation of PMMCs and the release of MCs-related mediators.

\section{Effects of VIP and aVIP on ETEC K88- and LPS-Induced Activation of PMMCs}

As shown in Figure 2, compared with the normal control group, both ETEC K88 and LPS induced a significant increase of the TNF- $\alpha$, IFN- $\gamma$, IL-6, IL- 8 , GM-CSF, $\beta$-hexosaminidase, tryptase and histamine levels in PMMCs supernatant. VIP significantly inhibited the increase of inflammatory factors, histamine, $\beta$ hexosaminidase and tryptase concentration in the supernatant of ETEC K88- and LPS-induced PMMCs. Administration with aVIP alone had no effect on ETEC K88- and LPS-induced activation of PMMCs. However, aVIP pretreatment 
A
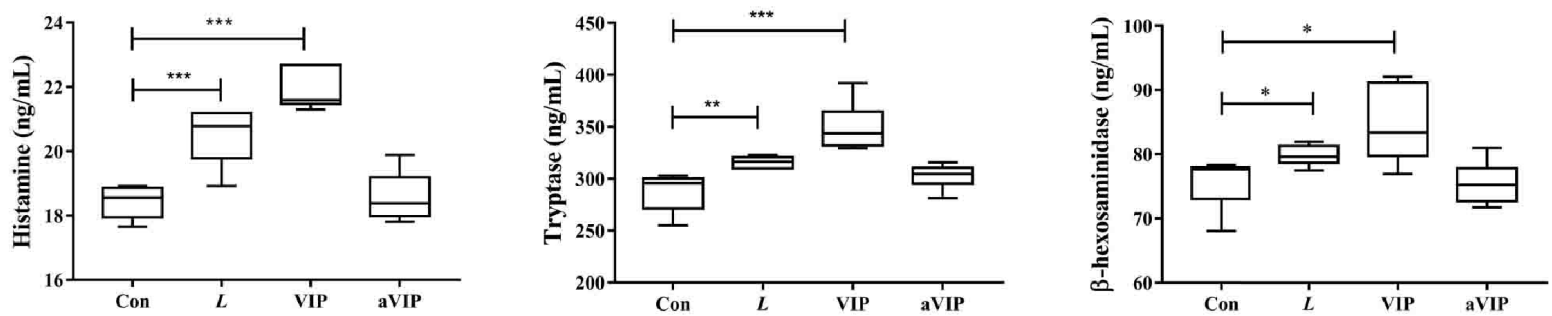

B
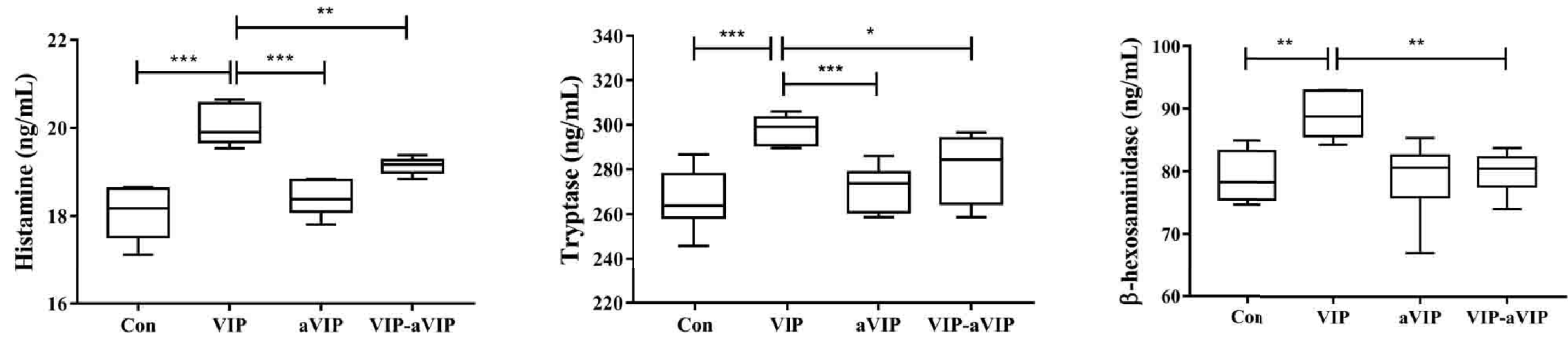

C
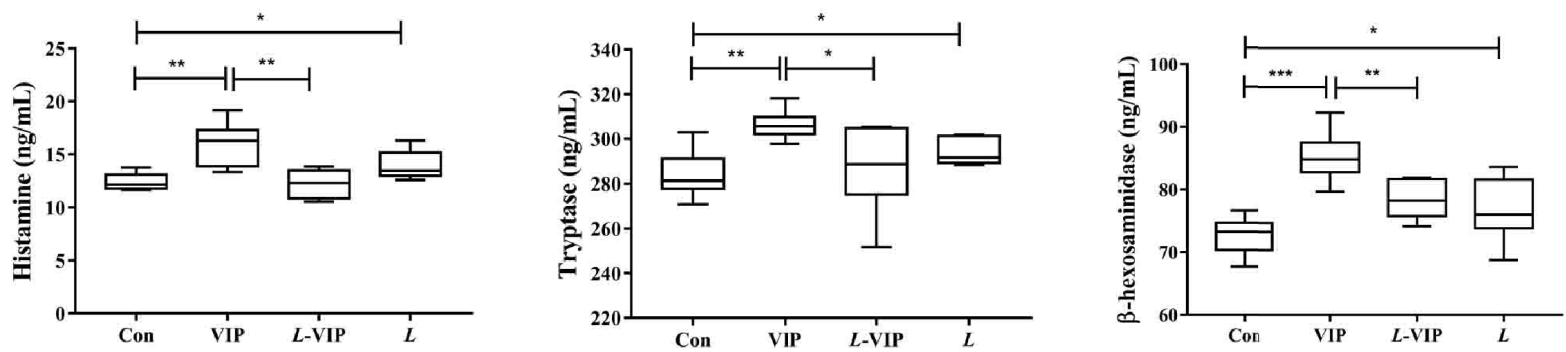

FIGURE 1 | Effect of $L$. casei ATCC 393, vasoactive intestinal peptide (VIP), VIP receptor antagonist (aVIP), and the interaction between VIP and aVIP, L. casei ATCC 393 and VIP on the activation of porcine mucosal mast cells (PMMCs). The cells were treated with the supernatants of $1 \times 10^{8}$ CFU/mL L. casei ATCC 393 culture medium for $12 \mathrm{~h}$. The cells were treated with $0.1 \mu \mathrm{M}$ VIP and aVIP in the same way. (A) The effect of $L$. casei ATCC 393 , VIP, aVIP on the activity of $\beta$ hexosaminidase, tryptase and the concentration of histamine in cell culture medium. (B) The effect of VIP and (or) aVIP on the activity of $\beta$-hexosaminidase, tryptase and the concentration of histamine in the cell culture medium. (C) The effect of $L$. casei ATCC 393 and (or) VIP on the activity of $\beta$-hexosaminidase, tryptase and the concentration of histamine in the cell culture medium. All data are presented as the mean \pm S.E.M. $(n=6)$. ${ }^{\star} P<0.05,{ }^{\star \star} P<0.01,{ }^{\star \star \star} P<0.001$. VIP means the PMMCs were exposed to VIP. $L$ means the PMMCs were exposed to $L$. casei ATCC 393. aVIP means the PMMCs were exposed to aVIP. aVIP-VIP means the PMMCs were exposed to VIP and aVIP. L-VIP means the PMMCs were exposed to L. casei ATCC 393 and VIP.

significantly inhibited the regulatory effect of VIP on ETEC K88and LPS-induced activation of PMMCs.

\section{Effects of aVIP and/or L.casei ATCC 393 on the Body Weight of Mice}

The change of body weight of the mice during the whole experiment is shown in Figure 3B. According to the overall trend, except for the ETEC K88-infected group and L. casei ATCC 393 protection group, the body weight of the other groups remained relatively stable. On the days 6 , from days 8 to 13 , the body weight of mice in the ETEC K88-infected group was significantly lower than that in the normal control group. The groups that were orally administered L. casei ATCC 393, aVIP and $L$. casei ATCC $393+$ aVIP all showed a significant alleviation of the reduction of body weight caused by ETEC K88. Moreover, the body weight of mice treated with $L$. casei ATCC 393 + ETEC K88+aVIP were significantly higher than that of mice in the $L$. casei ATCC 393 + ETEC K88 co-treated group.

\section{Effects of aVIP and/or L. casei ATCC 393 on Intestinal Morphology and Intestinal Barrier Function in Mice Challenged by ETEC K88}

As shown in Figures 4A, B, compared with the normal control group, infection by ETEC K88 caused a significant increase in crypt depth $(\mathrm{CD})$, a significant decrease in villus height $(\mathrm{VH})$ and VH/CD of duodenum. Orally administered L. casei ATCC 393 significantly alleviated the above phenomenon. However, compared with the ETEC K88-infected group, the administration of aVIP alone had no effect on the VH, CD and $\mathrm{VH} / \mathrm{CD}$ in mice exposed to ETEC K88. In addition, administration of aVIP significantly inhibited the effects of $L$. casei ATCC 393 on the VH, CD and VH/CD. As shown in Figure 4C, ETEC K88 significantly reduced the expression levels of ZO-1 and Occludin. L. casei ATCC 393 significantly alleviated the occurrence of the above phenomenon. aVIP showed antagonistic effect with $L$. casei ATCC 393 and inhibited the 

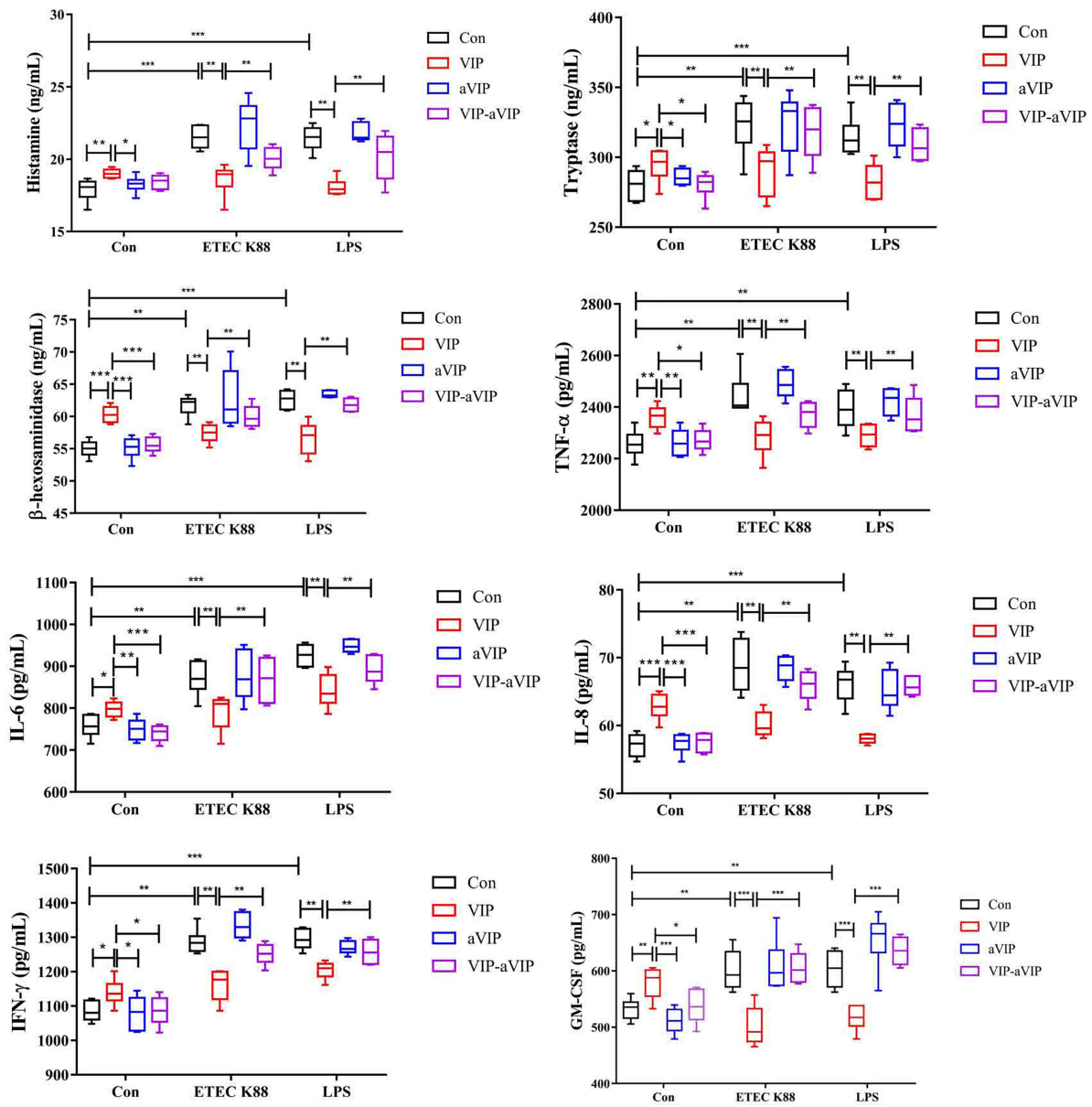

FIGURE 2 | Effect of the interaction between vasoactive intestinal peptide (VIP) and VIP receptor antagonist (aVIP) on the degranulation of porcine mucosal mast cells (PMMCs) induced by Enterotoxigenic Escherichia coli K88 (ETEC K88) and lipopolysaccharide (LPS). The cells were treated with the supernatants of $1 \times 10^{8}$ $\mathrm{CFU} / \mathrm{mL}$ of ETEC K88 culture medium and $0.1 \mu \mathrm{M}$ LPS for $2 \mathrm{~h}$. The cells were treated with $0.1 \mu \mathrm{M}$ VIP and aVIP for $12 \mathrm{~h}$. All data are presented as the mean \pm S.E.M. (n=6). ${ }^{\star} P<0.05,{ }^{\star \star} P<0.01,{ }^{\star \star}{ }^{\star} P<0.001$. VIP means the PMMCs were exposed to VIP. aVIP means the PMMCs were exposed to aVIP. aVIP-VIP means the PMMCs were exposed to VIP and aVIP.

protective effect of L. casei ATCC 393 on intestinal barrier function. As shown in Figure 4D, compared with the control group, the expression levels of MUC2 protein in ETEC K88 group was significantly increased. Administration of $L$. casei ATCC 393 significantly inhibited the above phenomenon. However, aVIP had antagonistic effect on the regulatory effect of L. casei ATCC 393. As shown in Figure 4E, L. casei ATCC 393 significantly alleviated the increase of MUC2 and Reg3g mRNA expression levels induced by ETEC K88. However, the regulatory effects of $L$. casei ATCC 393 on MUC2 expression was inhibited by aVIP under ETEC K88 challenge.

\section{Effects of aVIP and/or L. casei ATCC 393 on Intestinal Mucosal Immunity in Mice Challenged by ETEC K88}

TB staining of MCs in the proximal ileum of mice reveals, as shown in Figures 5A, B, that the number of total degranulated
MCs in the proximal ileum of ETEC K88-infected mice was significantly higher than that in the normal control mice. Also, L. casei ATCC 393 or (and) aVIP treatment significantly attenuated the ETEC K88-induced increase in the number of total degranulated MCs in the proximal ileum. However, compared with the L. casei ATCC 393 treatment group, i.p. administration of aVIP significantly inhibited the regulatory effect of $L$. casei ATCC 393 on ileal mucosal MCs in mice infected by ETEC K88. As shown in Figures 5C, D, compared with the normal control group, infection by ETEC K88 significantly increased serum TNF- $\alpha$, IL- 6 , IL- $1 \beta$, IFN- $\gamma$, VIP, $\operatorname{sIgA}$ and histamine levels, as well as the $\beta$-hexosaminidase, tryptase and MPO activities. However, pretreatment with $L$. casei ATCC 393 or (and) aVIP significantly inhibited the increase of TNF- $\alpha$, IL-6, IL-1 $\beta$, IFN- $\gamma$ levels, as well as the MPO activities induced by ETEC K88. L. casei ATCC 393 significantly inhibited the increase of sIgA and VIP levels induced by ETEC K88. Moreover, aVIP exhibited 
A

\section{C57BL/6}

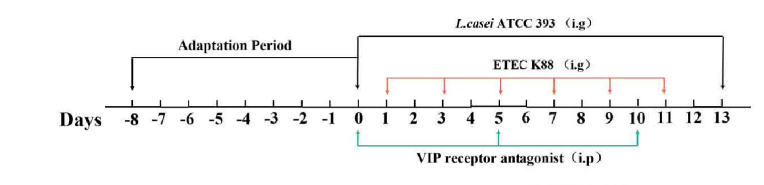

B

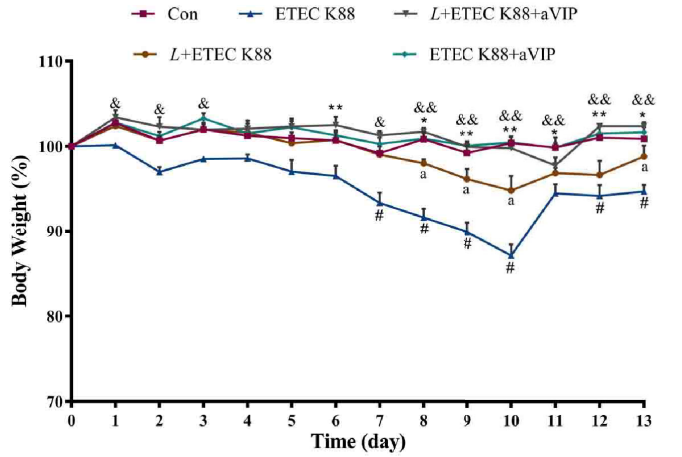

FIGURE 3 | The experimental scheme and the change of body weight during the entire experimental period. The concentrations of both L. casei ATCC 393 and ETEC K88 were $1 \times 10^{8} \mathrm{CFU} / \mathrm{mL}$, and the drug concentration of aVIP was $10 \mathrm{nmol} / \mathrm{kg}$ BW. (A) The experimental scheme. (B) The change of body weight. All data were presented as mean \pm S.E.M. $(n=10) .{ }^{*} P<0.05,{ }^{\star \star} P<0.01$; ${ }^{\sharp} P<0.05 ;{ }^{\&} P<0.05,{ }^{8 \&} P<0.01 ;{ }^{\mathrm{a}} P<0.05 .{ }^{*}$ means ETEC K88 infected group v.s. Con; \# means $L+a V I P+E T E C$ K88 v.s. ETEC K88 infective model group; \& means aVIP + ETEC K88 v.s. ETEC K88 infected group; a means $L+E T E C$ K88 v.s. ETEC K88 infected group. aVIP means the mice administered with the VIP receptor antagonist by i.p. injection. $L$ means the mice orally received L. casei ATCC 393. ETEC K88 means the mice orally received ETEC K88.

significantly antagonistic effect on the regulation of the release of TNF- $\alpha$, IL-6, IL-1 $\beta$, IFN- $\gamma$, VIP, sIgA and MCs-related mediators by L. casei ATCC 393.

\section{Effect of aVIP and/or L. casei ATCC 393 on The Microbial Community in Cecum of Mice Challenged by ETEC K88}

As shown in Figure 6A, compared with the other groups, administration of aVIP significantly increased the $\alpha$-diversity of cecum microbiome. As for the ACE, Chaol and Shannon index, there was no significant difference between each experimental group. As shown in Figure 6B, there was no significant difference for $\beta$-diversity in the genus level among each experimental group. In Figure 6C, there was no significant difference among those groups in the phylum level. However, as shown in Figures 6D, E, compared with the control, ETEC K88 significantly reduced the abundance of norank_f_Bacteroidales_S24-7_group. However, L. casei ATCC 393 and aVIP interventions alleviated the reduce of norank_f_Bacteroidales_S24-7_group. As shown in Figure 6F, LEfSe analysis showed that g_Lachnospiraceae_NK4A136_group and $g \_$Ruminococcus_ 1 were dominant species in mice challenged by ETEC K88, and g_unclassified_f_Peptostreptococcaceae and f_Peptostreptococcaceae were dominant species in mice administered with $L+E T E C$ K88.

\section{Effect of aVIP and/or L. casei ATCC 393 on the Mechanism of Intestinal Barrier Function}

As shown in Figures 7A, B, compared with the control group, ETEC K88 challenge improved the expression levels of MyD88, $\mathrm{p}-\mathrm{NF}-\kappa \mathrm{B}$ and TLR4. However, administration of L. casei ATCC 393 significantly inhibited the upregulation of MyD88, $\mathrm{p}-\mathrm{NF}-\kappa \mathrm{B}$ and TLR4 induced by ETEC K88. Moreover, aVIP intervention exhibited antagonistic effects on L. casei ATCC 393.

\section{DISCUSSION}

The intestinal mucosal immune barrier plays a critical role in maintaining host homeostasis $(24,25)$. Studies have shown that intestinal barrier dysfunction is closely associated with the occurrence and development of various diseases, such as inflammatory bowel disease (IBD), chronic kidney disease, type II diabetes, fatty liver and heart disease $(26,27)$. Intestinal symbiotic bacteria and exogenous probiotics work together to maintain the integrity of the intestinal barrier, meaning that probiotics protect the intestinal barrier function (28). Lactobacilli MTCC 5690, LrhS3, Lp9, Lp4 and Lr120 can improve intestinal barrier function through toll-like receptor 2 (TLR2)- and toll-like receptor 4 (TLR4)-mediated mechanism and regulation of the expression of mucin 2 (MUC2) and tight junction proteins (29). The mixed probiotics of bifidobacteria, Lactobacillus acidophilus and Enterococcus faecalis can reduce the dextran sodium sulfate salt (DSS)-induced intestinal inflammation, improve multiple barrier functions, increase mucosal integrity, enhance transepithelial electrical resistance, reduce the permeability of the epithelium and endothelium to macromolecules, and increase the abundance of bifidobacteria, lactobacillus and bacteroides (30). In this study, we found that oral administration of L. casei ATCC 393 effectively protected the intestinal histomorphology and intestinal barrier function, and improve the ETEC K88-induced cecum microbiome dysbiosis.

MCs are fundamental elements of the intestinal barrier (18), MCs as important immunological effector cells play a key regulatory role in adaptive and innate immunity (31). In pathological conditions, MCs release pro-inflammatory compounds, including cytokines (32). Our preliminary research indicated that $L$. casei ATCC 393 can relieve ETEC K88-induce intestinal barrier dysfunction via the TLRs/MCs pathway (14). However, the regulatory mechanism of the intestinal barrier function mediated by MCs has not been elucidated. According to the recent studies, it may be associated with the release of neurotransmitters (such as VIP, substance $\mathrm{P}$ ), and inflammatory mediators (such as cytokines) $(33,34)$. MCs not only senses the stimulation of harmful substances through the numerous receptors on their surface, including Fc receptor, complement receptor, TLRs, neuropeptide receptors, such as VPACs and antimicrobial peptide receptor, but also can synthesize and release transmitters to act on mucosal epithelium, nerve and other immune cells (35). As an extremely 
A

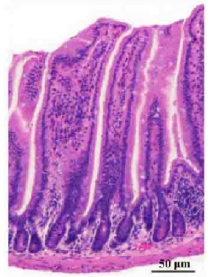

Con

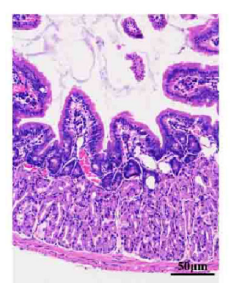

ETEC K88

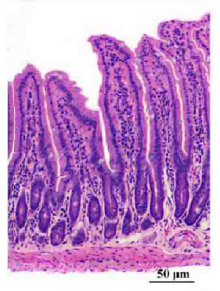

$L+$ ETEC K88+aVIP ETEC K88+aVIP

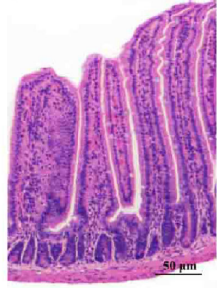

$L+$ ETEC K88

B
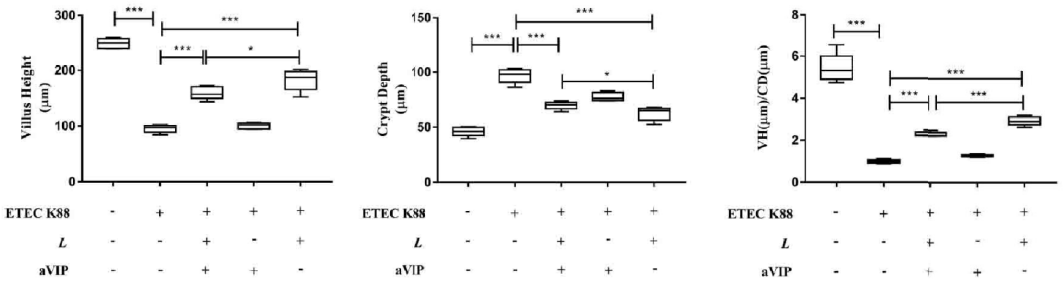

C
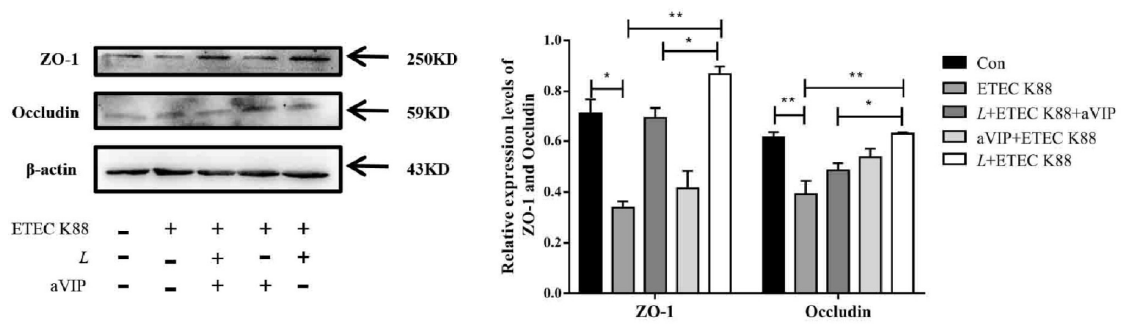

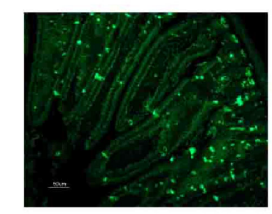

Con

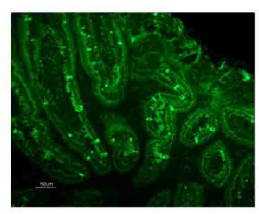

ETEC K88

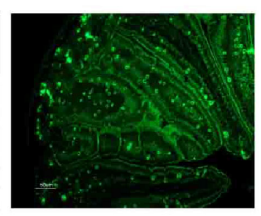

$L+$ ETEC K88+aVIP

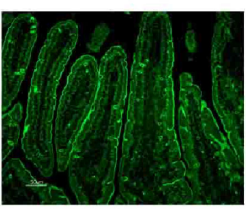

ETEC K88+aVIP

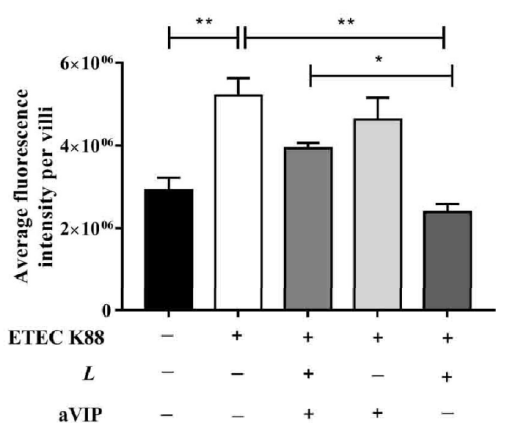

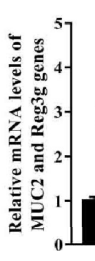

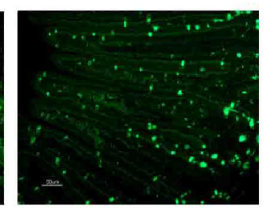

L+ETEC K88

FIGURE 4 | Effects of VIP receptor antagonist (aVIP) and L. casei ATCC 393 on intestinal barrier function. (A) The histomorphology of proximal duodenum was observed by hematoxylin-eosin (H\&E) staining. (B) Quantitative analysis of villus height and crypt depth. (C) Expression levels of tight junction proteins ZO-1 and Occludin. (D) Immunofluorescence of MUC2 protein in duodenum. (E) The expression levels of MUC2 and Reg3g genes. All data are presented as the mean \pm S.E.M. (n=4). ${ }^{*} P<$ $0.05,{ }^{\star \star} P<0.01,{ }^{\star \star \star} P<0.001$. aVIP means the mice were intraperitoneally (i.p.) injected with aVIP. $L$ means the mice orally received $L$. casei ATCC 393 . ETEC K88 means the mice orally received ETEC K88.

important neuroendocrine immunomodulatory peptide, VIP may be strongly associated with the regulation of intestinal barrier function (19). VIP can have a good therapeutic effect on necrotizing enterocolitis by reducing the inflammatory response and the destruction of TJ proteins (36). Furthermore, DSS induced colitis was associated with VIP and VPAC1 receptors (37). Moreover, VIP regulates a variety of immune cells, including MCs (38). VIP protects testis from torsion injury 
A

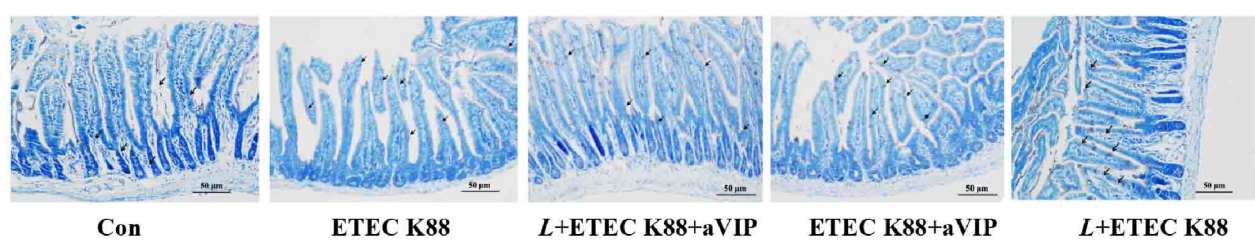

B

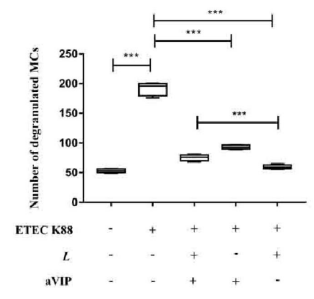

C

D
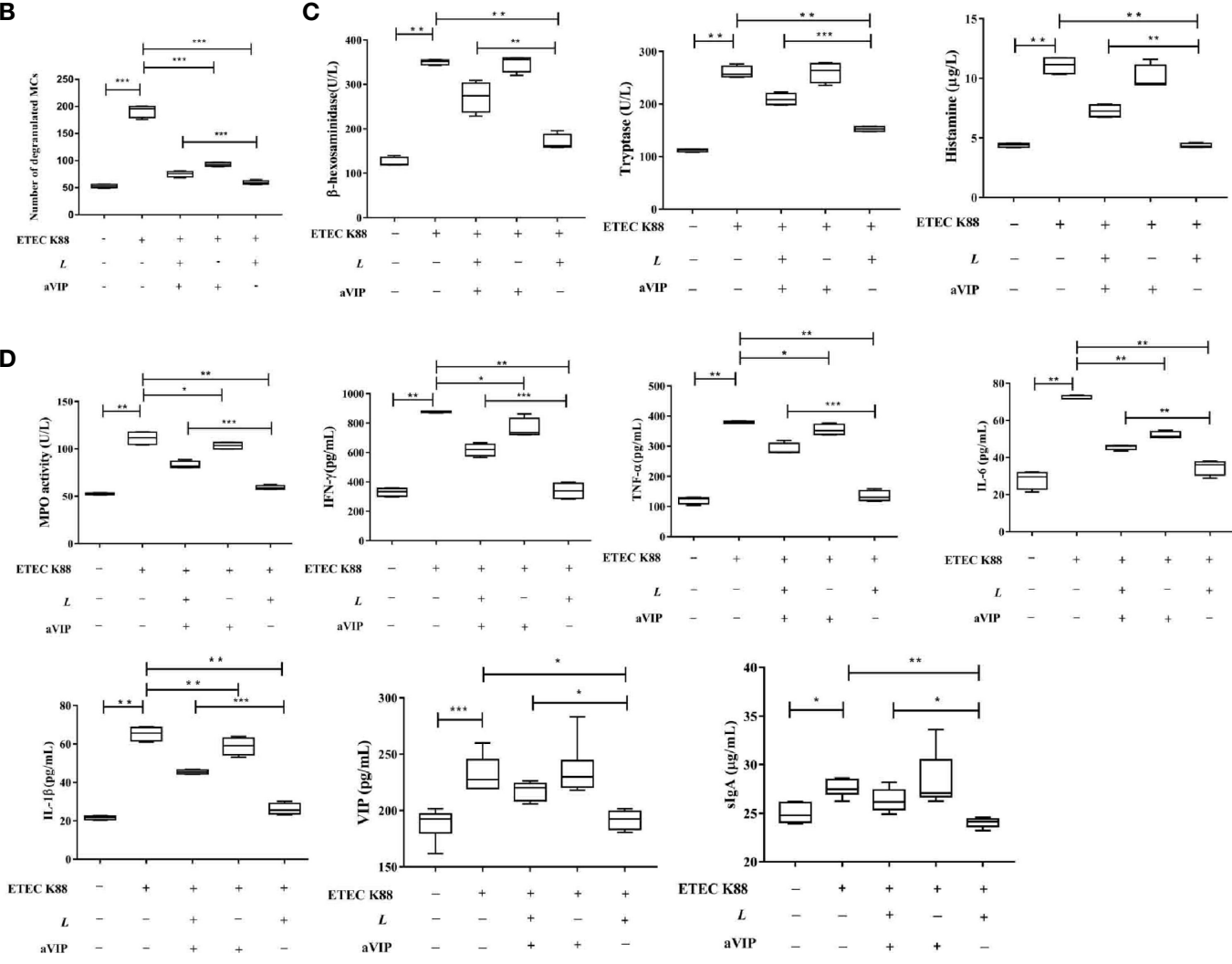

FIGURE 5 | Effect of VIP receptor antagonist (aVIP) and L. casei ATCC 393 on the number of degranulated mast cells (MCs) in the ileum of mice challenged by ETEC K88 and the release of mast cells (MCs)-related mediators. (A) The number of degranulated MCs in proximal ileum was observed by Toluidine Blue (TB) staining. (B) Quantitative analysis of the number of MCs. (C) Effects of VIP receptor antagonist (aVIP) and L. casei ATCC 393 on the release of mast cells (MCs)related mediators. (D) Effects of VIP receptor antagonist (aVIP) and L. casei ATCC 393 on serum myeloperoxidase (MPO) activity, VIP, slgA and cytokines levels in mice challenged by ETEC K88. All data are presented as the mean \pm S.E.M. $(n=4){ }^{\star} P<0.05,{ }^{\star \star} P<0.01,{ }^{* \star *} P<0.001$. aVIP means the mice were intraperitoneally (i.p.) injected with aVIP. $L$ means the mice orally received $L$. casei ATCC 393. ETEC K88 means the mice orally received ETEC K88.

by inhibiting the activation of MCs (39). Additionally, VIP can also play a protective role on septic mice by regulating the activation of MCs (40). In this study, we found that VIP promoted the activation of PMMCs, and inhibited the activation of PMMCs exposed to ETEC K88 or LPS. These results suggested that the regulatory effect of VIP on PMMCs activation was strongly associated with the physiological and pathological conditions of cells. However, L. casei ATCC 393 or the aVIP can inhibit the VIP-induced activation of PMMCs.

MCs are important mediators of allergic responses on host surfaces including the intestine. When MCs is challenged by an external stimulus, it may respond by degranulation. In this process, a number of powerful preformed inflammatory "mediators" are released, including cytokines, histamine, serglycin proteoglycans, and several MC-specific proteases: chymases, tryptases, and carboxypeptidase A (41). In this study, the high numbers of degranulated MCs were observed in mice exposed to ETEC K88. MCs not only senses the stimulation of harmful substances through many receptors on the surface (including Fc receptors, complement receptors, TLRs, neuropeptide receptors, antimicrobial peptide receptors, etc.), but also can synthesize and release transmitters to act on mucosal epithelium, nerve, and other immune cells (35). Intestinal flora not only produces ligands for 
A

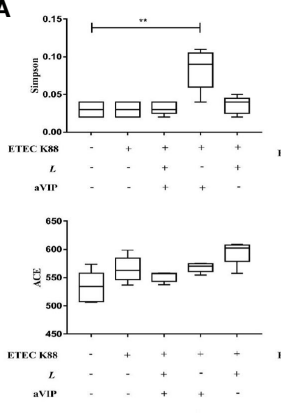

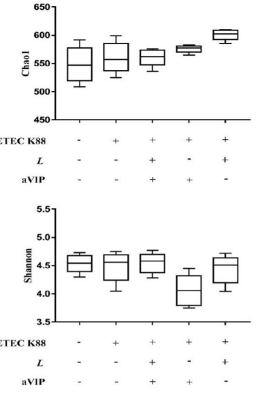

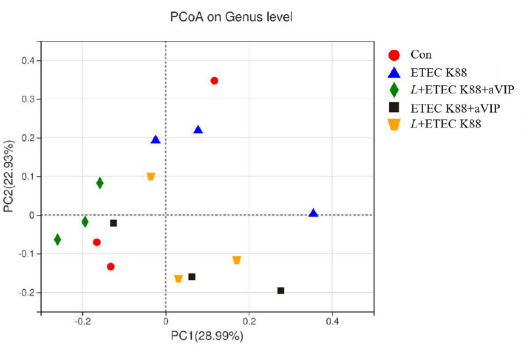

C

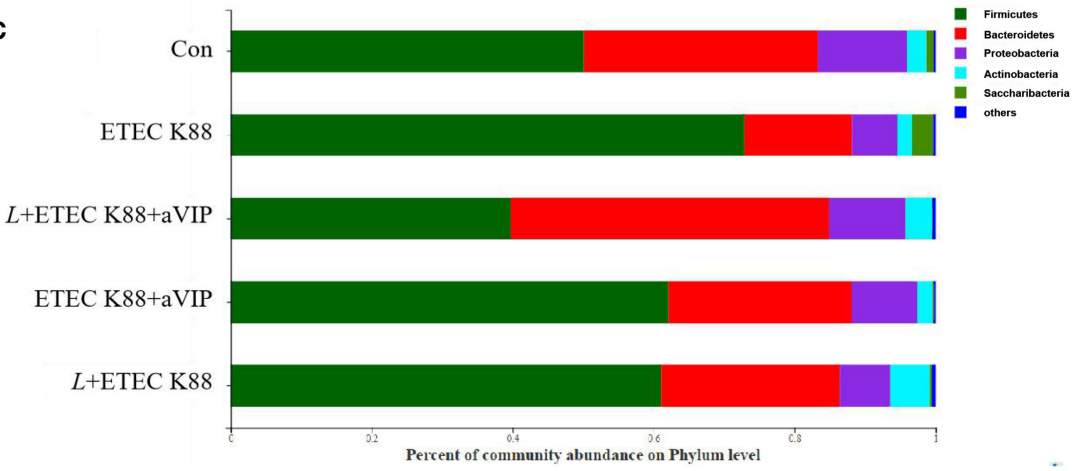

D

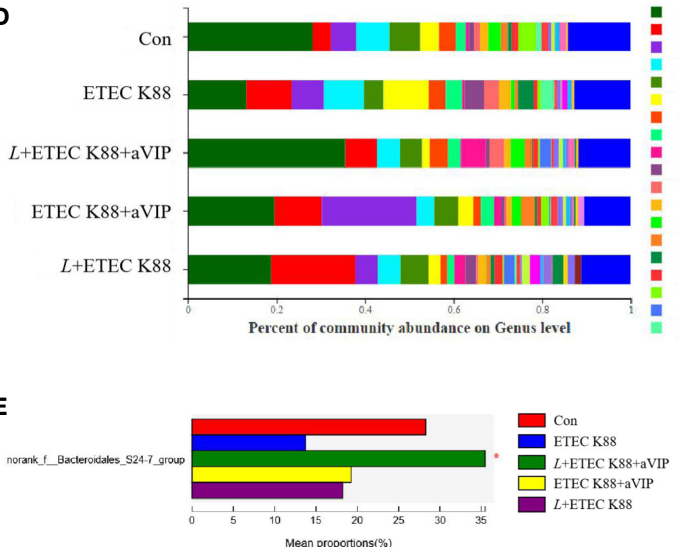

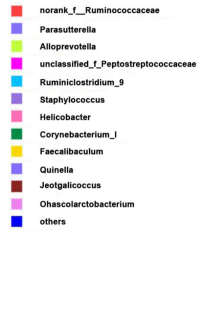

$\mathbf{F}$

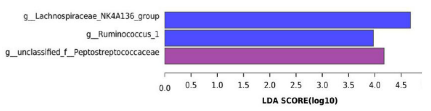

FIGURE 6 | Effect of $L$. casei ATCC 393 and VIP receptor antagonist (aVIP) on microbial community in cecum of mice challenged by ETEC K88. (A) $\alpha$-diversity analysis. (B) PCA plot of microbial community composition showed the compositional variance. (C) Differences in composition of microbial communities at phylum level. (D) Differences in composition of microbial communities at genus level. (E) LEfSe analysis of microbiota. All data are presented as the mean $\pm S$.E.M. ( $n=4)$. ${ }^{*} P<0.05,{ }^{* *} P<0.01$. aVIP means the mice were intraperitoneally (i.p.) injected with aVIP. $L$ means the mice orally received $L$. casei ATCC 393 . ETEC K88 means the mice orally received ETEC K88.

pattern recognition receptors (PRRs) (42), but also releases neurotransmitters and neuromodulators that target specific nervous systems on the brain-gut axis (43). If a TLR on MCs is activated, myeloid differentiation factor 88 (MyD88) and MyD88-adaptor like (MAL)/Toll-interleukin 1 receptor domain containing adaptor protein (TIRAP) associate and promote nuclear factor kappa-B $(\mathrm{NF}-\kappa \mathrm{B})$ translocation to the nucleus resulting in cytokines transcription (44). TLR4 can be activated by LPS from Gram-negative bacteria (45).
Antimicrobial peptides themselves have the function of protecting epithelial barrier and adjusting intestinal microbial balance (46). Probiotic L. rbamnosus Lc705 and L. rbamnosus GG could diminish mast cell activation (47). In this study, we observed that orally given L. casei ATCC 393 significantly inhibited the activation of ileal mucosal MCs in mice infected by ETEC K88. However, administration of aVIP by intraperitoneal injection abolished the regulatory effect of $L$. casei ATCC 393 on MCs activation in ileum, reduced the serum 


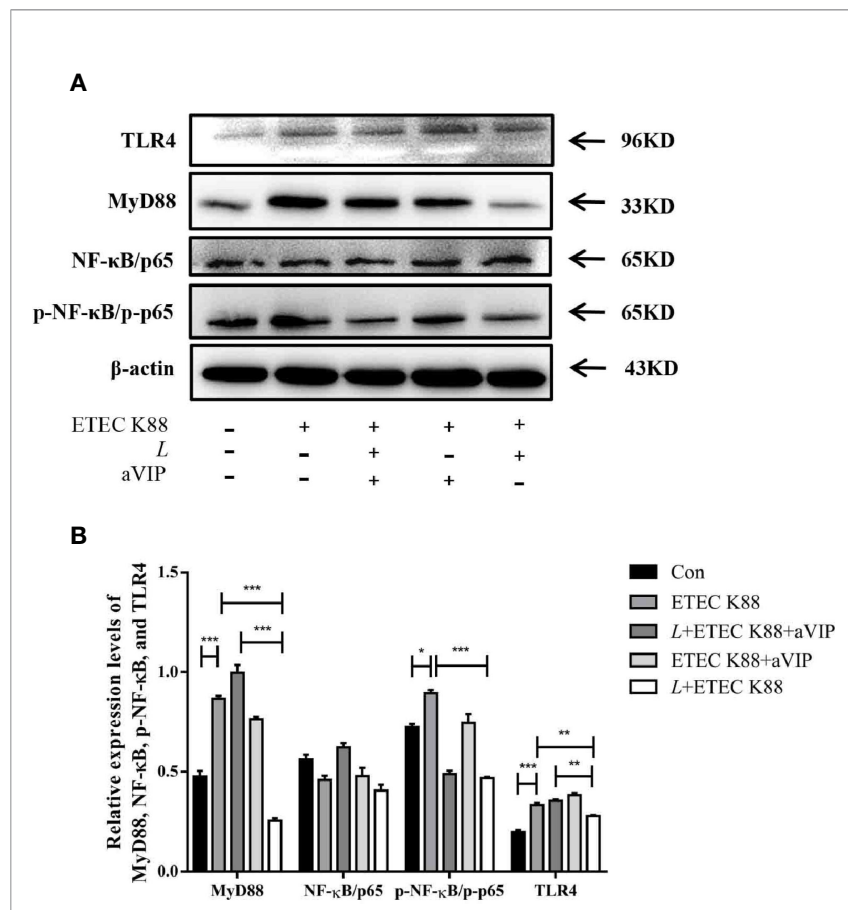

FIGURE 7 | Expression levels of relevant inflammatory markers. (A) The expression levels of related inflammatory markers were detected by Western Blot. (B) Quantitative statistical results. All data were presented as mean \pm S.E.M. (n=3). ${ }^{\star} P<0.05,{ }^{\star \star} P<0.01,{ }^{\star \star \star} P<0.001$.

VIP level, and alleviated the inflammatory response in ETEC K88-infected mice. aVIP $\left(\mathrm{VIP}_{6-28}\right)$ is the VIP receptor antagonist, which can competitively bound to the VPACs on the surface of MCs cells, counteracting the activation of endogenous VIP on MCs. In addition, administration of $L$. casei ATCC 393 or aVIP significantly alleviated the intestinal microbiome dysbiosis. Moreover, administration of $L$. casei ATCC 393 inhibited the activation of TLR4/MyD88/NF- $\mathrm{BB}$ signaling pathway induced by ETEC K88. VIP is an important secretomotor transmitter extensively expressed throughout the intestinal mucosa. Stress increased epithelial permeability, an effect that was largely blocked by a VIP receptor antagonist, and also the mast cell stabilizer doxantrazole (21). The above research results support the functional observations in the current study. The role of VIP in regulating antiinflammatory- proinflammatory balance and intestinal barrier function has been demonstrated in humans and mice (20,48, 49). The regulation of VIP on MC function may be bidirectional. It has been reported that VIP can affect the secretory activity of MCs, but the results are contradictory $(38,50)$. Therefore, the roles of VIP and mast cells in the regulatory effect of probiotics on intestinal barrier function require confirmation in further experiments.

\section{CONCLUSIONS}

The regulatory effect of VIP on MCs activation may be related to the physiological and pathological conditions of cells. L. casei
ATCC 393 inhibited the ETEC K88- and LPS-induced activation of intestinal mucosa MCs, and alleviated the intestinal mucosal injury in mice challenged by ETEC K88. VIP receptor antagonist abolished the protective effect of $L$. casei ATCC 393 on barrier function. Therefore, we speculated that the mechanism of L. casei ATCC 393 regulating intestinal mucosal injury may be related to VIP/MCs-mediated signaling pathway. However, the roles of VIP/MCs in the regulatory effects of probiotics on intestinal mucosal immune barrier function need further confirmation. This study is useful because it revealed the interaction of probiotics with enteric neuro-immunity and intestinal barrier function. L. casei ATCC 393 may be investigated as a potential and promising microecological food or feed additives in order to modulate intestinal barrier dysfunction.

\section{DATA AVAILABILITY STATEMENT}

The original contributions presented in the study are included in the article/supplementary material. Further inquiries can be directed to the corresponding authors.

\section{ETHICS STATEMENT}

The animal study was reviewed and approved by Laboratory Animal Welfare and Ethics Committee of Northwestern Polytechnical University.

\section{AUTHOR CONTRIBUTIONS}

XS: the design of this study, supervising of this project. SP: implementation of in vivo experiments, analysis and interpretation of data. YMG and FZ: critical revision of the article for important intellectual content. SY: implementation of in vitro experiments, analysis and interpretation of data. YC: critical revision of the article for important intellectual content. LQ: critical revision of the article for important intellectual content. XD: critical revision of the article for important intellectual content. All authors contributed to the article and approved the submitted version.

\section{FUNDING}

This work was supported by the National Natural Science Foundation of China (No.31672435 and No.32072746), the Key Research and Development Program of Shaanxi Province (No.2021NY-004), and Undergraduate Training Programs for Innovation and Entrepreneurship (No. S202010699424 and No. S202010699031X). 


\section{REFERENCES}

1. Pigrau M, Rodino-Janeiro BK, Casado-Bedmar M, Lobo B, Vicario M, Santos J, et al. The Joint Power of Sex and Stress to Modulate Brain-Gut-Microbiota Axis and Intestinal Barrier Homeostasis: Implications for Irritable Bowel Syndrome. Neurogastroenterol Motil (2016) 28:463-86. doi: 10.1111/nmo.12717

2. Hiippala K, Jouhten H, Ronkainen A, Hartikainen A, Kainulainen V, Jalanka J, et al. The Potential of Gut Commensals in Reinforcing Intestinal Barrier Function and Alleviating Inflammation. Nutrients (2018) 10:988. doi: 10.3390/nu10080988

3. Bron PA, Kleerebezem M, Brummer RJ, Cani PD, Mercenier A, MacDonald TT, et al. Can Probiotics Modulate Human Disease by Impacting Intestinal Barrier Function? Br J Nutr (2017) 117:93-107. doi: 10.1017/ S0007114516004037

4. Shah A, Talley NJ, Jones M, Kendall BJ, Koloski N, Walker MM, et al. Small Intestinal Bacterial Overgrowth in Irritable Bowel Syndrome: A Systematic Review and Meta-Analysis of Case-Control Studies. Am J Gastroenterol (2020) 115:195-201. doi: 10.14309/ajg.0000000000000504

5. Sanchez B, Delgado S, Blanco-Miguez A, Lourenco A, Gueimonde M, Margolles A. Probiotics, Gut Microbiota, and Their Influence on Host Health and Disease. Mol Nutr Food Res (2017) 61:1600240. doi: 10.1002/mnfr.201600240

6. Saxelin M, Tynkkynen S, Mattila-Sandholm T, de Vos WM. Probiotic and Other Functional Microbes: From Markets to Mechanisms. Curr Opin Biotechnol (2005) 16:204-11. doi: 10.1016/j.copbio.2005.02.003

7. Prisciandaro LD, Geier MS, Butler RN, Cummins AG, Howarth GS. Evidence Supporting the Use of Probiotics for the Prevention and Treatment of Chemotherapy-Induced Intestinal Mucositis. Crit Rev Food Sci Nutr (2011) 51:239-47. doi: 10.1080/10408390903551747

8. Bekkali NLH, Bongers MEJ, Van den Berg MM, Liem O, Benninga MA. The Role of a Probiotics Mixture in the Treatment of Childhood Constipation: A Pilot Study. Nutr J (2007) 6:17. doi: 10.1186/1475-2891-6-17

9. Llopis M, Antolin M, Carol M, Borruel N, Casellas F, Martinez C, et al. Lactobacillus Casei Downregulates Commensals' Inflammatory Signals in Crohn's Disease Mucosa. Inflammation Bowel Dis (2009) 15:275-83. doi: 10.1002/ibd.20736

10. Lee B, Yin X, Griffey SM, Marco ML. Attenuation of Colitis by Lactobacillus Casei BL23 Is Dependent on the Dairy Delivery Matrix. Appl Environ Microbiol (2015) 81:6425-35. doi: 10.1128/AEM.01360-15

11. Aktas B, De Wolfe TJ, Safdar N, Darien BJ, Steele JL. The Impact of Lactobacillus Casei on the Composition of the Cecal Microbiota and Innate Immune System Is Strain Specific. PLoS One (2016) 11:e0156374. doi: 10.1371/journal.pone.0156374

12. Aktas B, De Wolfe TJ, Tandee K, Safdar N, Darien BJ, Steele JL. The Effect of Lactobacillus Casei $32 \mathrm{G}$ on the Mouse Cecum Microbiota and Innate Immune Response Is Dose and Time Dependent. PLoS One (2015) 10:e0145784. doi: 10.1371/journal.pone.0145784

13. Mathipa MG, Thantsha MS, Bhunia AK. Lactobacillus Casei Expressing Internalins A and B Reduces Listeria Monocytogenes Interaction With Caco-2 Cells In Vitro. Microb Biotechnol (2019) 12:715-29. doi: 10.1111/ 1751-7915.13407

14. Xu C, Yan S, Guo Y, Qiao L, Ma L, Dou X, et al. Lactobacillus Casei ATCC 393 Alleviates Enterotoxigenic Escherichia Coli K88-Induced Intestinal Barrier Dysfunction via TLRs/mast Cells Pathway. Life Sci (2020) 244:117281. doi: $10.1016 /$ j.lfs.2020.117281

15. Krystel-Whittemore M, Dileepan KN, Wood JG. Mast Cell: A MultiFunctional Master Cell. Front Immunol (2015) 6:620. doi: 10.3389/ fimmu.2015.00620

16. Santos J, Yang PC, Söderholm JD, Benjamin M, Perdue MH. Role of Mast Cells in Chronic Stress Induced Colonic Epithelial Barrier Dysfunction in the Rat. Gut (2001) 48:630-6. doi: 10.1136/gut.48.5.630

17. de Almeida AD, Silva IS, Fernandes-Braga W, LimaFilho ACM, Florentino ROM, Barra A, et al. A Role for Mast Cells and Mast Cell Tryptase in Driving Neutrophil Recruitment in LPS-Induced Lung Inflammation via ProteaseActivated Receptor 2 in Mice. Inflamm Res (2020) 69:1059-70. doi: 10.1007/ s00011-020-01376-4

18. Marcelino da Silva EZ, Jamur MC, Oliver C. Mast Cell Function: A New Vision of an Old Cell. J Histochem Cytochem (2014) 62:698-738. doi: 10.1369/ 0022155414545334
19. Albert-Bayo M, Paracuellos I, Gonzalez-Castro AM, Rodriguez-Urrutia A, Rodriguez-Lagunas MJ, Alonso-Cotoner C, et al. Intestinal Mucosal Mast Cells: Key Modulators of Barrier Function and Homeostasis. Cells (2019) 8:135. doi: 10.3390/cells8020135

20. Conlin VS, Wu X, Nguyen C, Dai C, Vallance BA, Buchan AM, et al. Vasoactive Intestinal Peptide Ameliorates Intestinal Barrier Disruption Associated With Citrobacter Rodentium-Induced Colitis. Am J Physiol Gastrointest Liver Physiol (2009) 297:G735-50. doi: 10.1152/ajpgi.90551.2008

21. Keita AV, Carlsson AH, Cigehn M, Ericson AC, McKay DM, Soderholm JD. Vasoactive Intestinal Polypeptide Regulates Barrier Function via Mast Cells in Human Intestinal Follicle-Associated Epithelium and During Stress in Rats. Neurogastroenterol Motil (2013) 25:e406-17. doi: 10.1111/nmo.12127

22. Zhang H, Yan Y, Shi R, Lin Z, Wang M, Lin L. Correlation of Gut Hormones With Irritable Bowel Syndrome. Digestion (2008) 78:72-6. doi: 10.1159/000165352

23. Lin R, Sun Y, Ye W, Zheng T, Wen J, Deng Y. T-2 Toxin Inhibits the Production of Mucin via Activating the IRE1/XBP1 Pathway. Toxicology (2019) 424:152230. doi: 10.1016/j.tox.2019.06.001

24. France MM, Turner JR. The Mucosal Barrier at a Glance. J Cell Sci (2017) 130:307-14. doi: 10.1242/jcs.193482

25. Branca JJV, Gulisano M, Nicoletti C. Intestinal Epithelial Barrier Functions in Ageing. Ageing Res Rev (2019) 54:100938. doi: 10.1016/j.arr.2019.100938

26. Zaylaa M, Al Kassaa I, Alard J, Peucelle V, Boutillier D, Desramaut J, et al. Probiotics in IBD: Combining In Vitro and In Vivo Models for Selecting Strains With Both Anti-Inflammatory Potential as Well as a Capacity to Restore the Gut Epithelial Barrier. J Funct Foods (2018) 47:304-15. doi: 10.1016/j.jff.2018.05.029

27. Ghosh SS, Wang J, Yannie PJ, Ghosh S. Intestinal Barrier Function and Metabolic/ Liver Diseases. Liver Res (2020) 4:81-7. doi: 10.1016/j.livres.2020.03.002

28. Knackstedt R, Gatherwright J. The Role of Thermal Injury on Intestinal Bacterial Translocation and the Mitigating Role of Probiotics: A Review of Animal and Human Studies. Burns (2020) 46:1005-12. doi: 10.1016/ j.burns.2019.07.007

29. Rokana N, Mallappa RH, Batish VK, Grover S. Interaction Between Putative Probiotic Lactobacillus Strains of Indian Gut Origin and Salmonella: Impact on Intestinal Barrier Function. Lwt (2017) 84:851-60. doi: 10.1016/ j.lwt.2016.08.021

30. Chen Y, Zhang L, Hong G, Huang C, Qian W, Bai T, et al. Probiotic Mixtures With Aerobic Constituent Promoted the Recovery of Multi-Barriers in DSS-Induced Chronic Colitis. Life Sci (2019) 240:117089. doi: 10.1016/j.lfs.2019.117089

31. Afrin LB, Khoruts A. Mast Cell Activation Disease and Microbiotic Interactions. Clin Ther (2015) 37:942-53. doi: 10.1016/j.clinthera.2015.02.008

32. Conti P, Lauritano D, Caraffa A, Gallenga CE, Kritas SK, Ronconi G, et al. Microglia and Mast Cells Generate Proinflammatory Cytokines in the Brain and Worsen Inflammatory State: Suppressor Effect of IL-37. Eur J Pharmacol (2020) 875:173035. doi: 10.1016/j.ejphar.2020.173035

33. Alonso C, Vicario M, Pigrau M, Lobo B, Santos J. Intestinal Barrier Function and the Brain-Gut Axis. Adv Exp Med Biol (2014) 817:73-113. doi: 10.1007/ 978-1-4939-0897-4_4

34. Wouters MM, Vicario M, Santos J. The Role of Mast Cells in Functional GI Disorders. Gut (2016) 65:155-68. doi: 10.1136/gutjnl-2015-309151

35. Theoharides TC, Alysandratos KD, Angelidou A, Delivanis DA, Sismanopoulos N, Zhang B, et al. Mast Cells and Inflammation. Biochim Biophys Acta (2012) 1822:21-33. doi: 10.1016/j.bbadis.2010.12.014

36. Seo S, Miyake H, Alganabi M, Janssen Lok M, O'Connell JS, Lee C, et al. Vasoactive Intestinal Peptide Decreases Inflammation and Tight Junction Disruption in Experimental Necrotizing Enterocolitis. J Pediatr Surg (2019) 54:2520-3. doi: 10.1016/j.jpedsurg.2019.08.038

37. Yadav M, Huang MC, Goetzl EJ. VPAC1 (Vasoactive Intestinal Peptide (VIP) Receptor Type 1) G Protein-Coupled Receptor Mediation of VIP Enhancement of Murine Experimental Colitis. Cell Immunol (2011) 267:124-32. doi: 10.1016/j.cellimm.2011.01.001

38. Tuncel N, Sener E, Cerit C, Karasu U, Gurer F, Sahinturk V, et al. Brain Mast Cells and Therapeutic Potential of Vasoactive Intestinal Peptide in a Parkinson's Disease Model in Rats: Brain Microdialysis, Behavior, and Microscopy. Peptides (2005) 26:827-36. doi: 10.1016/j.peptides.2004.12.019

39. Can C, Tore F, Tuncel N, Uysal O, Gurer F, Ak D, et al. Protective Effect of Vasoactive Intestinal Peptide on Testicular Torsion-Detorsion Injury: Association With Heparin-Containing Mast Cells. Urology (2004) 63:195200. doi: 10.1016/j.urology.2003.08.010 
40. Tuncel N, Tore F, Sahinturk V, Ak D, Tuncel M. Vasoactive Intestinal Peptide Inhibits Degranulation and Changes Granular Content of Mast Cells: A Potential Therapeutic Strategy in Controlling Septic Shock. Peptides (2000) 21:81-9. doi: 10.1016/S0196-9781(99)00177-1

41. Pejler G, Abrink M, Ringvall M, Wernersson S. Mast Cell Proteases. Adv Immunol (2007) 95:167-255. doi: 10.1016/S0065-2776(07)95006-3

42. Mu CL, Yang YX, Zhu WY. Crosstalk Between the Immune Receptors and Gut Microbiota. Curr Protein Pept Sci (2015) 16:622-31. doi: 10.2174/ 1389203716666150630134356

43. Holzer P, Farzi A. Neuropeptides and the Microbiota-Gut-Brain Axis. Adv Exp Med Biol (2014) 817:195-219. doi: 10.1007/978-1-4939-0897-4_9

44. Basu S, Fenton MJ. Toll-Like Receptors: Function and Roles in Lung Disease. Am J Physiol Lung Cell Mol Physiol (2004) 286:L887-92. doi: 10.1152/ ajplung.00323.2003

45. Honda K, Taniguchi T. IRFs: Master Regulators of Signalling by Toll-Like Receptors and Cytosolic Pattern-Recognition Receptors. Nat Rev Immunol (2006) 6:644-58. doi: 10.1038/nri1900

46. Zong X, Fu J, Xu B, Wang Y, Jin M. Interplay Between Gut Microbiota and Antimicrobial Peptides. Anim Nutr (2020) 6:389-96. doi: 10.1016/ j.aninu.2020.09.002

47. Oksaharju A, Kankainen M, Kekkonen RA, Lindstedt KA, Kovanen PT, Korpela R, et al. Probiotic Lactobacillus Rhamnosus Downregulates FCER1 and HRH4 Expression in Human Mast Cells. World J Gastroenterol (2011) 17:750-9. doi: 10.3748/wjg.v17.i6.750

48. Morampudi V, Conlin VS, Dalwadi U, Wu X, Marshall KC, Nguyen C, et al. Vasoactive Intestinal Peptide Prevents Pkce-Induced Intestinal Epithelial Barrier Disruption During EPEC Infection. Am J Physiol
Gastrointest Liver Physiol (2015) 308:G389-402. doi: 10.1152/ajpgi. 00195.2014

49. Neunlist M, Toumi F, Oreschkova T, Denis M, Leborgne J, Laboisse CL, et al. Human ENS Regulates the Intestinal Epithelial Barrier Permeability and a Tight Junction-Associated Protein ZO-1 via VIPergic Pathways. Am J Physiol Gastrointest Liver Physiol (2003) 285:G1028-36. doi: 10.1152/ajpgi.00066.2003

50. Stewart MJ, Emery DL, McClure SJ, Bendixsen T. The Effects of Four Neuropeptides on the Degranulation of Mucosal Mast Cells From Sheep. Immunol Cell Biol (1996) 74:255-7. doi: 10.1038/icb.1996.45

Conflict of Interest: The authors declare that the research was conducted in the absence of any commercial or financial relationships that could be construed as a potential conflict of interest.

Publisher's Note: All claims expressed in this article are solely those of the authors and do not necessarily represent those of their affiliated organizations, or those of the publisher, the editors and the reviewers. Any product that may be evaluated in this article, or claim that may be made by its manufacturer, is not guaranteed or endorsed by the publisher.

Copyright (c) 2021 Song, Pi, Gao, Zhou, Yan, Chen, Qiao, Dou, Shao and Xu. This is an open-access article distributed under the terms of the Creative Commons Attribution License (CC BY). The use, distribution or reproduction in other forums is permitted, provided the original author(s) and the copyright owner(s) are credited and that the original publication in this journal is cited, in accordance with accepted academic practice. No use, distribution or reproduction is permitted which does not comply with these terms. 